\title{
Single intramuscular dose toxicokinetics of manganese in broiler chicks
}

\author{
Muna Al-Zubaidy, Fouad Kasim Mohammad \\ Department of Physiology, Biochemistry and Pharmacology, \\ College of Veterinary Medicine, University of Mosul, P. O. Box 11136, Mosul, I raq \\ Corresponding author: Fouad Kasim Mohammad, e-mail: fouadmohammad@yahoo.com \\ Received: 29-03-2012, Accepted: 16-04-2012, Published Online: 19-06-2012 \\ doi: $10.5455 /$ vetworld.2012.560-564
}

\begin{abstract}
Aim: Manganese (Mn) produces neurobehavioral toxicity in various animal species including the young chicks. The present study examines toxicokinetics of Mn in 7-10-day old chicks after an intramuscular injection at $20 \mathrm{mg} / \mathrm{kg}$.

Materials and Methods: Samples of the blood, whole brain, liver and kidney were obtained from chicks (5/each time period) at 0 time (base-line) and then at times between 0.17 to $4 \mathrm{~h}$. The concentrations of $\mathrm{Mn}$ in the plasma and tissues were determined by atomic absorption spectrometry. Toxicokinetic parameters of $\mathrm{Mn}$ were calculated from the mean metal concentrations in the plasma by a non-compartmental analysis using a Windows-based computer program.

Results: Injection of Mn significantly increased the metal levels in the plasma, whole brain, liver and kidney of the chicks when compared to respective base-line control values at times 0.17 to $4 \mathrm{~h}$ after the injection (with the exception at 2 and $4 \mathrm{~h}$ in the brain). The highest concentration of $\mathrm{Mn}$ in the plasma and the whole brain appeared one $\mathrm{h}$ after the injection, whereas those of the liver and kidney appeared $4 \mathrm{~h}$ post-injection. The concentrations of $\mathrm{Mn}$ in the plasma ranged between 0.43 to 1.2 $\mu \mathrm{g} / \mathrm{ml}$ within 0.17 to $4 \mathrm{~h}$. Those of the whole brain, liver and kidney were $0.11-0.46,6.3-15$ and $5.3-22.9 \mu \mathrm{g} / \mathrm{g}$, respectively. The elimination half-life of Mn was $3.02 \mathrm{~h}$ with steady state volume of distribution $24.34 \mathrm{~L} / \mathrm{kg}$ and total body clearances of $4.78 \mathrm{~L} / \mathrm{h} / \mathrm{kg}$. The mean residence time of $\mathrm{Mn}$ was $5.09 \mathrm{~h}$ and its area under the plasma concentration-time curve $(0-\infty)$ was 4.18 $\mu \mathrm{g} . \mathrm{h} / \mathrm{ml}$. The elimination half-life of $\mathrm{Mn}$ from the brain was $3.12 \mathrm{~h}$ with an elimination rate constant of $0.22 \mathrm{~h}-1$.

Conclusion: The data suggest that $\mathrm{Mn}$ is well absorbed and rapidly distributed after an intramuscular administration in chicks and further support the reported neurobehavioral toxic effects of the metal which are observed within one $h$ after treatment. Key words: Chick; Half-life; Manganese; Neurotoxicity; Toxicokinetics.
\end{abstract}

To cite thisarticle:

Al-Zubaidy M, Mohammad FK (2012) Single intramuscular dose toxicokinetics of manganese in broiler chicks, Vet World, 5(9): 560-564, doi: 10.5455/vetworld.2012.560-564

\section{I ntroduction}

Manganese (Mn) is known to be a neurotoxicant because of high industrial exposure level in man [1-3]. The neurotoxicity of $\mathrm{Mn}$ has been reproduced and characterized in various animal species including mainly rats and mice [4-8] with few studies in the avian species $[9,10]$. The neurobehavioral effects of Mn in man and animals include disturbances of locomotor activity and alteration of cognitive behaviors $[3,8,11$ 13]. A recent study also described a potential neurotoxicity model of Mn in broiler chicks [10].

The toxicokinetic and pharmacokinetic aspects of $\mathrm{Mn}$ and its tissue distribution are critical points for evaluating the toxicity and potential harmful effects of the metal [14-17]. Such information are important in the risk assessment of the metal [17-19]. The toxic effects of Mn might be associated with the differential accumulation of the metal in different organ systems of the body $[16,18]$. For example, the neurochemical and neurobehavioral changes induced by Mn could be correlated with the differential accumulation of the metal in different regions of the brain $[6,20]$. Plasma, bone and tissue levels of $\mathrm{Mn}$ are additionally used as diagnostic or biomarker endpoints of exposure [21-23].

The kinetic behavior of $\mathrm{Mn}$ has been described in several animal species with wide range of tissue distributions [14, 16, 18, 21]. In chicks, Mn administration at 10 to $100 \mathrm{mg} / \mathrm{kg}$, intramuscularly (i.m.) produced high levels of the metal in the plasma, brain, liver and kidney [10]. Further, Mn administrations at 5,10 and $20 \mathrm{mg} / \mathrm{kg}$, i.m. were found to alter the locomotor activity and other behavioral performance in 7-14 days old broiler chicks [10]. However, the 
Table-1. Manganese concentrations in the plasma $(\mu \mathrm{g} / \mathrm{ml})$ and tissues $(\mu \mathrm{g} / \mathrm{g})$ of chicks after a single intramuscular administration at a dose of $20 \mathrm{mg} / \mathrm{kg}$ body weight

\begin{tabular}{lllll}
\hline Time (h) & Plasma & Brain & Liver & Kidney \\
\hline 0 & $0.10 \pm 0.05^{*}$ & $0.11 \pm 0.02^{*}$ & $0.58 \pm 0.05^{*}$ & $0.3 \pm \pm 0.05^{*}$ \\
0.17 & $0.43 \pm 0.23$ & $0.35 \pm 0.05$ & $10.3 \pm 2.3$ & $5.3 \pm 1.2$ \\
0.33 & $0.49 \pm 0.23$ & $0.27 \pm 0.03$ & $10.8 \pm 2.5$ & $7.2 \pm 2.1$ \\
0.50 & $0.66 \pm 0.26$ & $0.37 \pm 0.02$ & $7.7 \pm 2.3$ & $10.5 \pm 2.4$ \\
0.75 & $0.69 \pm 0.16$ & $0.38 \pm 0.04$ & $13.3 \pm 1.7$ & $12.0 \pm 4.2$ \\
1.0 & $1.20 \pm 0.73$ & $0.46 \pm 0.05$ & $6.3 \pm 2.5$ & $12.2 \pm 5.4$ \\
1.5 & $0.88 \pm 0.09$ & $0.17 \pm 0.03$ & $11.2 \pm 2.5$ & $15 \pm 4.7$ \\
2.0 & $0.49 \pm 0.03$ & $0.15 \pm 0.02^{\mathrm{a}}$ & $15 \pm 1.1$ & $2.9 \pm 5.3$ \\
4.0 & $0.54 \pm 0.36$ & $0.11 \pm 0.02^{\mathrm{a}}$ & & \\
\hline
\end{tabular}

Values are mean \pm SE of 5 chicks/each sampling time. *Significantly different (except those with the superscript letter a) from respective concentrations between 0.17 to $4 \mathrm{~h}$ after the Mn injection, $\mathrm{p}<0.05$.

toxicokinetics of Mn are not known in chicks which could be used as an animal model of neurotoxicity induced by the metal. The purpose of the present study was to examine toxicokinetics of $\mathrm{Mn}$ administered at $20 \mathrm{mg} / \mathrm{kg}$, i.m. in broiler young chicks.

\section{Materials and Methods}

One-day-old broiler chicks of both sexes obtained from a local hatchery were housed at room temperature of $32^{\circ} \mathrm{C}$ to $35^{\circ} \mathrm{C}$ with constant lighting, and floor litter consisted of wood shavings. Water and feed were available ad libitum. We performed the toxicokinetic experiment on 45 chicks when they became 7-10 days old. The Scientific Committee of the College of Veterinary Medicine at the University of Mosul has reviewed and approved the protocol of the study in chicks. All the experiments complied with institutional regulations addressing animal use, and proper attention and care were given to the chicks used in this study.

We prepared the injectable solution of $\mathrm{Mn}$ at 20 $\mathrm{mg} / \mathrm{kg}$ by dissolving $\mathrm{Mn}$ chloride $\left(\mathrm{MnCl}_{2} \cdot 4 \mathrm{H}_{2} \mathrm{O}\right.$, Avishkar, India) in unionized distilled water. The volume of administration was at $5 \mathrm{ml} / \mathrm{kg}$, i.m. The choice of this dosage was based on our previous study in which Mn was found to induce behavioral changes in chicks [10]. Blood samples (1-2 ml) were collected from chicks (5/each sampling time) by jugular vein bleeding into heparinized test tubes [24] at 0 time (base-line) and then at times of 0.17, 0.33, 0.50, 0.75, $1,1.50,2$ and $4 \mathrm{~h}$ after $\mathrm{Mn}$ administration. Thereafter, the chicks were euthanized by cervical dislocation to obtain the whole brain, liver and kidneys. Plasma was separated from erythrocytes by centrifugation of blood samples at $3000 \mathrm{rpm}$ (Centurion, U.K.) for 15 minutes. Plasma and tissue samples were stored at $-18^{\circ} \mathrm{C}$ pending $\mathrm{Mn}$ determination within $48 \mathrm{~h}$. The plasma and tissue samples were digested in $65 \%$ nitric acid with $24 \mathrm{~h}$ incubation at $70^{\circ} \mathrm{C}$ [25]. The concentration of Mn was determined using atomic absorption spectrometry (Novaa 350, Germany) with UV-visible lamp and air-acetylene burner.

To reduce individual variations in the plasma concentrations of $\mathrm{Mn}$, means of plasma concentrations of $\mathrm{Mn}$ at each sampling time $(0.17-4 \mathrm{~h})$ were used to calculate the toxicokinetic parameters by a noncompartmental analysis [26,27] using a Windowsbased computer program [28]. The toxicokinetic variables included in the calculations were: area under plasma concentration-time curve $\left(\mathrm{AUC}_{0-\infty}\right)$, area under the moment curve $\left(\mathrm{AUMC}_{0-\infty}\right)$ from time zero to infinity, elimination half-life $\left(\mathrm{t}_{1 / 2 \mathrm{~B}}\right)$, elimination rate constant $\left(\mathrm{k}_{\mathrm{el}}=0.693 / \mathrm{t}_{1 / 2 \mathrm{~B}}\right)$, steady state volume of distribution $\left[\mathrm{V}_{\mathrm{ss}}=\right.$ Dose.AUMC/ $\left.(\mathrm{AUC})^{2}\right]$, maximum $\mathrm{Mn}$ concentration (Cmax), time to maximum $\mathrm{Mn}$ concentration (Tmax), mean residence time (MRT=AUMC/AUC) and total clearance $(\mathrm{CL}=$ Dose/AUC). Furthermore, using a semi log paper, the $\mathrm{t}_{1 / 2 \mathrm{~B}}$ and $\mathrm{k}_{\mathrm{el}}$ of brain $\mathrm{Mn}$ were calculated from $\mathrm{Mn}$ concentrations in the brain starting from Tmax at one $h$ and then including the rest of the values until $4 \mathrm{~h}$ after the injection.

The differences of $\mathrm{Mn}$ concentrations in the plasma and tissues were statistically analyzed by analysis of variance followed by the least significant difference test [29]. The level of significance was at $p<$ 0.05 .

\section{Results}

Injection of Mn at the dose rate of $20 \mathrm{mg} / \mathrm{kg}$, i.m. significantly and variably increased the metal levels in the plasma, whole brain, liver and kidney of the chicks when compared to respective base-line ( 0 time) control values at times 0.17 to $4 \mathrm{~h}$ after the injection (with the exception at 2 and $4 \mathrm{~h}$ in the brain), (Table 1 ). The highest concentration of $\mathrm{Mn}$ in the plasma and the whole brain appeared one $\mathrm{h}$ after the injection, 
Table-2. Toxicokinetic parameters of manganese in chicks after a single intramuscular administration at a dose of $20 \mathrm{mg} / \mathrm{kg}$ body weight

\begin{tabular}{|c|c|c|}
\hline Variable* & Unit & Value \\
\hline Mean residence time (MRT=AUMC/AUC) & $\mathrm{h}$ & 5.09 \\
\hline Steady state volume of distribution [Vss=Dose.AUMC/ $\left.(\mathrm{AUC})^{2}\right]$ & $\mathrm{L} / \mathrm{kg}$ & 24.34 \\
\hline Elimination rate constant $\left(\mathrm{k}_{\mathrm{el}}=0.693 /{ }_{\mathrm{t} 1 / 2 \mathrm{~B}}\right)$ & $\mathrm{h}^{-1}$ & 0.23 \\
\hline Tmax & $\mathrm{h}$ & 1 \\
\hline Cmax & $\mu \mathrm{g} / \mathrm{ml}$ & 1.2 \\
\hline Total clearance (CL=Dose/AUC) & $\mathrm{L} / \mathrm{h} / \mathrm{kg}$ & 4.78 \\
\hline
\end{tabular}

* The means of plasma concentrations of manganese at each sampling time (0.17-4 h) were used to calculate the toxicokinetic parameters by a non-compartmental analysis using a Windows-based computer program [28]. $n=5 \mathrm{chicks} /$ each sampling time.

whereas those of the liver and kidney appeared $4 \mathrm{~h}$ post-injection (Table 1). The concentrations of $\mathrm{Mn}$ in the plasma ranged between 0.43 to $1.2 \mu \mathrm{g} / \mathrm{ml}$ within 0.17 to $4 \mathrm{~h}$ (Table 1 ). Those of the whole brain, liver and kidney were $0.11-0.46,6.3-15$ and $5.3-22.9 \mu \mathrm{g} / \mathrm{g}$, respectively (Table 1 ).

The toxicokinetic parameters of Mn calculated from the mean $\mathrm{Mn}$ concentrations in the plasma at times 0.17 to $4 \mathrm{~h}$ in chicks are shown in Table 2. The elimination half-life of $\mathrm{Mn}$ was $3.02 \mathrm{~h}$ with steady state volume of distribution $24.34 \mathrm{~L} / \mathrm{kg}$ and total body clearance of $4.78 \mathrm{~L} / \mathrm{h} / \mathrm{kg}$. The mean residence time of $\mathrm{Mn}$ was $5.09 \mathrm{~h}$ and its area under the plasma concentration-time curve ( 0 -alpha) was $4.18 \mu \mathrm{g} . \mathrm{h} / \mathrm{ml}$. Other related toxicokinetic parameters are also listed in table 2. The elimination half-life of Mn from the brain was $3.12 \mathrm{~h}$ with an elimination rate constant of $0.22 \mathrm{~h}^{-1}$.

\section{Discussion}

Manganese is widely distributed into various organs of the body and the metal burden correlates with toxic effects seen in the tissues [14-18, 21]. High levels of $\mathrm{Mn}$ are also attained in the plasma, brain, liver and kidney of chicks following the injection of the metal at doses ranged between $10-100 \mathrm{mg} / \mathrm{kg}$, i.m. [10]. The findings of the present study are the first systemic toxicokinetic report of $\mathrm{Mn}$ in young chicks following its injection at $20 \mathrm{mg} / \mathrm{kg}$, i.m. This dosage of $\mathrm{Mn}$ was reported to alter general locomotor activity of the chicks with indications of central depressant action [10]. The appearance of $\mathrm{Mn}$ in the plasma and the tissues especially in the brain within one h correlates with the behavioral changes reported in chicks within one $h$ too [10]. The Cmax and Tmax values indicate that $\mathrm{Mn}$ is relatively rapidly absorbed into the systemic circulation of the chicks. High concentrations of Mn occurred in the kidney followed by the liver and the brain. In rats, Mn highly accumulates in the liver followed by the kidney and the heart at $2 \mathrm{~h}$ following an intravenous injection of $\mathrm{MnCl}_{2}$ [30]. Appearance of $\mathrm{Mn}$ in the liver and kidney at high concentrations reflects the metabolic and excretory pathways of the metal within $4 \mathrm{~h}[14,30,31]$. The pattern of $\mathrm{Mn}$ accumulation in the brain which is the target organ for the induction of neurobehavioral changes, depends on the chemical formulation of the metal and its route of administration $[6,20]$. Mn readily enters the brain of younger animals compared to adults [32-34]. This favors the use of young chicks for monitoring the neurotoxic effect of Mn. Mn enters the brain through blood capillaries or by influx into the cerebrospinal fluid and across the choroid plexus $[35,36]$. Injection of radioactive $\mathrm{Mn}$ into the blood circulation results within one $\mathrm{h}$ in the accumulation of the metal in the choroid plexus [37]. Generally, increased plasma and tissue Mn levels are considered as biomarkers of the metal exposure [21-23].

The toxicokinetic parameters of the present study suggest that Mn is well absorbed and distributed in the body of the chicks with a $\mathrm{V}_{\mathrm{ss}}$ of $24.34 \mathrm{~L} / \mathrm{kg}$ and eliminated relatively within a day $(\mathrm{CL} 4.78 \mathrm{~L} / \mathrm{h} / \mathrm{kg}$ and $t_{1 / 2}$ 3.02). $V_{s s}$ is a reliable estimate of volume of distribution, since it is calculated independent of the $\mathrm{k}_{\mathrm{el}}$ $[26,27]$. Increased levels of tissue Mn burden after systemic administration are in support of its high volume of distribution [14,16,18,21,30]. However, $\mathrm{Mn}$ is almost completely eliminated from the body within 5 days in rats [14,30,31]. The reported elimination half-life of $\mathrm{Mn}$ in rats is $4.56 \mathrm{~h}$ [14]. In our study it was $3.02 \mathrm{~h}$. It should be expected that differences in the toxicokinetics of Mn would exist among various laboratory animal species. The variations in the kinetic parameters of Mn across various animal species could be attributed to the differences in the dosage and its form, chemical formulation, route of administration and species variation $[6,14,16,18,20$, 
21,30,31]. The $t_{1 / 2 B}$ of $M n$ in the brain was almost identical to that of the plasma (3.12 vs. $3.07 \mathrm{~h})$. It was reported that $\mathrm{Mn}$ is slowly eliminated from the brain once it is accumulated there [32-34]. We did not observe this phenomenon in our current experiment. This could be attributed to the young age of the chicks used (7-10 days) as $\mathrm{Mn}$ is retained to a considerable extent in the brain of the adult animal only [20,32-34]. The data suggest that $\mathrm{Mn}$ is well absorbed and rapidly distributed after an i.m. administration in chicks and further support the reported neurobehavioral toxic effects of the metal which are observed within one $h$ after treatment.

\section{Author's contribution}

MAZ executed the experiments, shared in statistical analysis and shared in drafting the manuscript. FKM conceptualized the study, designed the experiment, supervised dosing regimen as well as data analysis, shared in statistical analysis and drafted the manuscript in English. All authors read and approved the final manuscript.

\section{Acknowledgements}

This report represents a portion of a dissertation to be submitted by the first author to the University of Mosul, Iraq as partial fulfillment of the requirements of $\mathrm{PhD}$ degree in Veterinary Toxicology. This study was supported by the College of Veterinary Medicine, University of Mosul, Iraq.

\section{Competing interest}

Authors declares that they have no competing interest.

\section{References}

1. Iregren, A. (1999). Manganese neurotoxicity in industrial exposure: proof of effects, critical exposure level and sensitive tests. Neurotoxicology, 20:315-323.

2. Normandin, L., Panisset, M. and Zayed, J. (2002). Manganese neurotoxicity: behavioral, pathological, and biochemical effects following various routes of exposure. Rev. Environ. Health, 17: 189-217.

3. Wang, X., Yang, Y., Wang, X. and Xu, S. (2006). The effect of occupational exposure to metals on the nervous system function in welders. J. Occup. Health, 48: 100-106.

4. Newland, M.C. (1999). Animal models of manganese's neurotoxicity. Neurotoxicology, 20: 415-432.

5. Talavera, E.J., Arcaya, J.L., Giraldoth, D., Suarez, J. and Bonilla, E. (1999). Decrease in spontaneous motor activity and in brain lipid peroxidation in manganese and melatonin treated mice. Neurochem. Res., 24: 705-708.
6. Normandin, L., Beaupre, L.A., Salehi, F., St.-Pierre, A., Kennedy, G., Mergler, D., Butterworth, R.F., Philippe, S. and Zayed, J. (2004). Manganese distribution in the brain and neurobehavioral changes following inhalation exposure of rats to three chemical forms of manganese. Neurotoxicology, 25: 433-441.

7. Torrente, M., Colomina, M.T. and Domingo, J.L. (2005). Behavioral effects of adult rats concurrently exposed to high doses of oral manganese and restraint stress. Toxicology, 211:59-69.

8. Fordahl, S., Cooney, P., Qiu, Y., Xie, G., Jia, W. and Erikson, K.M. (2012). Waterborne manganese exposure alters plasma, brain, and liver metabolites accompanied by changes in stereotypic behaviors. Neurotoxicol. Teratol., 34: 27-36.

9. Mohammad, F.K. and Faris, G.A-M. (2006). Behavioral effects of acute manganese chloride administration in chickens. Biol. Trace. Elem. Res., 110: 265-274.

10. Al-Zubaidy, M.H.I. and Mohammad, F.K. (2012). Potential chick model of acute manganese neurotoxicity. Submitted to Arch. Indus. Hyg. Toxicol.

11. Shukakidze, A., Lazriev, I. and Mitagvariya, N. (2003). Behavioral impairments in acute and chronic manganese poisoning in white rats. Neurosci. Behav. Physiol., 33:263-267.

12. Bast-Pattersen, R., Ellingsen, D.G., Hetland, S.M. and Thomassen, Y. (2004). Neuropsychological function in manganese alloy plant workers. Int. Arch. Occup. Environ. Health, 77: 277-287.

13. Bowler, R.M., Gocheva, V., Harris, M., Ngo, L., Abdelouahab, N., Wilkinson, J., Doty, R.L., Park, R. and Roels, H.A. (2011). Prospective study on neurotoxic effects in manganese-exposed bridge construction welders. Neurotoxicology, 32: 596-605.

14. Zheng, W., Kim, H. and Zhao, Q. (2000). Comparative toxicokinetics of manganese chloride and methyl cyclopentadienyl manganese tricarbonyl (MMT) in Sprague-Dawley rats. Toxicol. Sci., 54: 295-301.

15. Erikson, K.M., John, C.E., Jones, S.R. and Aschner, M. (2005). Manganese accumulation in striatum of mice exposed to toxic doses is dependent upon a functional dopamine transporter. Environ. Toxicol. Pharmacol., 20:390-394.

16. Miles, R.D. and Henry, P.R. (2006). Relative trace mineral bioavailability. Cienc. Anim. Bras., 1:73-92.

17. Santamaria, A.B. and Sulsky, S.I. (2010). Risk assessment of an essential element: manganese. $J$. Toxicol. Environ. Health, 73: 128-155.

18. Andersen, M.E., Dorman, D.C., Clewell, H.J., Taylor, M.D. and Nong, A. (2010). Multidose-route, multispecies pharmacokinetic models for manganese and their use in risk assessment. J. Toxicol. Environ. Health, A 73: 217-234.

19. Aschner, M., Tomás, R., Guilarte, J., Schneider, S. and Zheng, W. (2007). Manganese: recent advances in understanding its transport and neurotoxicity. Toxicol. Appl. Pharmacol., 221: 131-147.

20. Gianutsos, G., Seltzer, M.D., Saymeh, R., Wu, M-LW. 
and Michel, R.G. (1985). Brain manganese accumulation following systemic administration of different forms. Arch. Toxicol., 57: 272-275.

21. Salehi, F., Krewski, D., Mergler, D., Normandin, L., Kennedy, G., Philippe, S. and Zayed, J. (2003). Bioaccumulation and locomotor effects of manganese phosphate/sulfate mixture in Sprague-Dawley rats following subchronic (90 days) inhalation exposure. Toxicol. Appl. Pharmacol., 191:264-271.

22. Hoet, P., Vanmarcke, E., Geens, T., Deumer, G., Haufroid, V. and Roels, H.A. (2011). Manganese in plasma: a promising biomarker of exposure to $\mathrm{Mn}$ in welders. Apilot study. Toxicol. Lett., (in press).

23. Zheng, W., Fu, S.X., Dydak, U. and Cowan, D.M (2011). Biomarkers of manganese intoxication. Neurotoxicology, 32: 1-8.

24. Stevens, R.W.C. and Ridgway, G. J. (1966). A technique for bleeding chickens from the jugular vein. Poult. Sci., 45: 204-205.

25. Lamphere, D.N., Dorn, C.R., Reddy, C.S. and Meyer, A.W. (1984). Reduced cadmium body burden in cadmium-exposed calves fed supplemental zinc. Environ. Res., 33: 119-129.

26. Gibaldi M., Perrie, D. (1982): Pharmacokinetics. 2nd ed. New York: Marcel Dekker.

27. Baggot, J.D. (2001). The Physiological Basis of Veterinary Clinical Pharmacology. Oxford: Blackwell Science.

28. Laub, P.B. and Gallo, J.M. (1996). NCOMP-a windows-based computer program for noncompartmental analysis of pharmacokinetic data. J. Pharm.
Sci., 85: 393-395.

29. Petrie, A. and Watson, P. (1999). Statistics for Veterinary and Animal Sciences. Oxford: Blackwell Science.

30. Klaassen, C. D. (1974). Biliary excretion of manganese in rats, rabbits, and dogs. Toxicol. Appl. Pharmacol., 29: 458-468.

31. EPA (1993). Research and Development. Drinking water criteria document for manganese. Cincinnati, OH, USA: US Environmental Protection Agency.

32. Cahill, D.F., Bercegeay, M.S., Haggerty, R.C., Gerding, J.E. and Gray, L.E. (1980). Age-related retention and distribution of ingested $\mathrm{Mn}_{3} \mathrm{O}_{4}$ in the rat. Toxicol.Appl.Pharmacol., 53: 83-91.

33. Mena, I., Horiuchi, K. and Lopez, G. (1974). Factors enhancing entrance of manganese into the brain: iron deficiency and age. J. Nucl. Med., 15:516.

34. Rehnberg, G.L., Hein, J.F., Carter, S.D., Linko, R.S. and Laskey, J.W. (1981). Chronic ingestion of $\mathrm{Mn}_{3} \mathrm{O}_{4}$ by young rats: tissue accumulation, distribution, and depletion. J. Toxicol. Environ. Health, 7: 263-272.

35. Murphy, V.A., Wadhwani, K.C., Smith, Q.R., Rapoport, S.I. (1991). Saturable transport of manganese (II) across the rat blood-brain barrier. $J$. Neurochem., 57: 948-954.

36. Rabin, O., Hegedus, L., Bourre, J.M., Smith, Q.R. (1993). Rapid brain uptake of manganese(II) across the blood-brain barrier. J. Neurochem., 61:509-517.

37. Takeda, A., Akiyama, T., Sawashita, J. and Okada, S. (1994). Brain uptake of trace metals, zinc and manganese, in rats. Brain Res., 640: 341-344. 